\title{
Strategy of Stable Development of Russian Modern Educationas Multi-dimensional Methodological Phenomenon
}

\author{
Gaponyuk P. N. ${ }^{1}$, MareevV. I. ${ }^{2}$, Karpova N. K. ${ }^{3, *}$, Schipankina E. S. ${ }^{3}$ \\ ${ }^{1}$ Russian Academy of Education, Head of Human Resources and International Relations Department, Moscow, 119121, Russia \\ ${ }^{2}$ SouthernFederalUniversity, Rostov-on-Don, 344082, Russia \\ ${ }^{3}$ SouthernFederalUniversity, sub-faculty of Pedagogy, Rostov-on-Don, 344082, Russia
}

\begin{abstract}
Theartic lecovers strategic forecasting of Russian educationalsystem development. The authors give outline of the key featuresproviding stable development of education referred to as "points of growth" and dealing with regional programs. The article also defines the functions of indicative management and indicative planning in the development of educational system and presents the methodology of indicative management as a multi-dimensional phenomenon. Interdisciplinary character of the issue under study is considered as a functional block supportingstability in multi-dimensionality and is characterized by a number of concepts. These concepts among others include the following: «upbringing or personality development», «indicative management model of educational system development».
\end{abstract}

Keywords Strategic Forecasting, Forecasting in Education, Stable Develop ment, Methodology ofMulti-Dimensionality, Concepts, Upbringing or Personality Development, Indicative Management, Interdisciplinary Character

\section{Introduction}

The given research objective is to define the concepts describing methodological mult idimensionality in education. The basic premise is that the scope of the concepts is multi-dimensional and this multi-dimensionality is implemented into practice in the form of interdisciplinary approach. The concepts "upbringing" and "indicative management of educational systems development" are treated as mainvectors for implementing programs aimed at strategy of steady development of modern education in Russia. Indicative management enables to regulate functioning and development of educational systems. Upbringingor personality development characterizes cultural -educational reality of modern Russia by a number of concepts.These concepts are aimed at providing high quality in education. Quality is considered as the basis for strategic management in educational systems development.

We also set the following objectives: to offer irre futable proof of the urgent need to make forecasts in education development; to consider education development from the point of view of its local features; to single out "points of growth" in the stable development of education in Russia;

* Corresponding author:

karpova_nk@mail.ru (Karpova N.K.)

Published online at http://journal.sapub.org/edu

Copyright (C) 2012 Scientific \& Academic Publishing. All Rights Reserved to reveal the peculiarities of the objects of management as the factor of indicative planning; to describe the concepts of "indicative management model of educational systems"in terms of multi-dimensional methodology.

\section{Strategic Forecasting Methodology as the Basis of Regional Educational SystemsStable Development}

Management of education as a dynamic system requires forecasts on the prospects of its development in order to make necessary managing decision. The quality of human (intellectual) assets and the efficiency of economics in general depend on the quality of forecasting, assessments and their efficient use in the process of educational system management.

Strategic forecasting is defined as a scientifically grounded activity focused on the research of possible transformations, on developing tendencies and prospects of subjects and objects of pedagogical activity[1].

Forecast is a probabilistic assessment of future results and ways of educationalsystem development. It also covers the resources and activities, requiredto make it come true.

Forecasting is seen as an objective necessity. In order to achieve the necessary high quality of education, the system requires a well-managed interference into development of Russian education as evolutionary development of educational system doesn't meet modern social demands. 
It should be noted that educational system belongs to the most popular spheres of activity being at the same time the most significant component of social life. Thus, stable development of education as a social system and institution, as well as stable developmentmanagement,are possible when the following key principle-principle of social suitability of projecting changes-is followed. This principle should lead to such results that meet the demands of the society. The problem of regulating regional education development processes has become urgent. Stable development of the educational system is guaranteed by the balanced development of territorial educational systems. Development is the second step. It implies transformation of educational system, changing the number, parameters, qualitative features of former components, connections between them and their balance.

Forecasting in education is intended to provide positive balanced dynamics of regional educational programs development. Territorial aspectof balanced components of educational system development supports stable development of Russian educational system. At the beginning of XXI century,Russiafaces all features of international tendencies and principles that are typical of the period of active regionalization and globalization (glocalization) processes of social development occurring simultaneously. A whole number of typically Russian features, having objective and pers istent character,combined with temporary circumstances of transition period, make the regional situation in Russia rather specific. The following circumstances should be accounted as the most significant: dramatic changes in production placement and caused by them changes in urban settlements life, historically accumulated and springing up problems of federate relations, dramatic transformation of the network and activity of municipal institutions, specific forms of interaction between regional authorities and business, low efficiency of the use of traditional mechanisms for solving regional problems as well as administrative-and-management novelties of the period referred to as "vertical power consolidation". All these factors are under influence of the high level and constant consolidation of territorial differentiation.

The problem of quality of education management viewed at a new perspective has become quite topical. It concerns achieving the balance of new positive changes in regional educational systems, involving indicative planning. Strategic forecasting of Russian educational system development should include a regional aspect as an obligatory feature. Stable developmentcorrelates with highlighting certain "points of growth". "Points of growth" mean those regional programs that are the most significant for education today. They should be supported by the government in the first place. Thus, forecasting stable development in educationmeans selecting is sues of highest priority for governmental support and business investments.

\subsection{State Regulation of Education Functioning and Development basing on Indicative Management and Indicative Planning}

It should be noted that education, on the one hand, is quasi-natural, i.e. considered in terms of objectively existing reality, and, on the other hand, a subjectively constructed and managed process. The main feature of education management under modern conditions is that the problems of education should be solved not only at the educational system level. Solution of these problems is one of the components of the government policy.

Indicative management can be considered as an instrument for the state regulation of functioning and development of educational system.

Generally speaking, indicative management is the method of economics regulation basing on integrity of interrelated and well-balanced management objectives resulted from forecasting, criteria or management efficiency assessment, mechanisms of interrelation with other methods of regulation, including the following: marketing, monitoring, conception of economic growth, etc. Indicative management is based on the harmonization of actions by authorities and institutions arranging the system of education, focused on stable development in education and improving its quality.

Analyticalstage of indicative management is referred to as planning. Indicative planning is of recommendation character and allows makingdevelopment plan in terms of problematic sphere of educational establishments and society, balancing conflicting interests of business and the government.

Indicative planning of education system development is treated as an institutionally isolated block of the indicative planning of Russian economy development. Conceptual features of the indicative planning of Russian social and economic development are universal for all economic sectors, including education. Thus, indicative planning in management of governmental economy, decomposed in all blocks, enables to coordinate managing process es to achieve efficient development in both institutionalized sectors (subsystems) of economy and governmental economy in general.

It's also worth noting that it's impossible to fail to fulfil indicative plan. One can only fail to reach it. The failure to reach the indicators of indicative plan stipulates the necessity to analyse the reasons why the plan appeared inefficient and to work outsomemeasures for its correction. Theymay include definition of itsnorms, regulators andlimits.

Indicative planning means defining economic priorities. The essence of indicative planning process is similar to the process of consulting, the main functions of which being providing information, outlining key perspectives and stimulation.

Planning stipulates organization, fulfilment, control and monitoring of the results and then making decisionsbasing on the resultsachieved. In this respect, implementation presupposes adequate level of the resourcesrequired for the set goals, timeframes and order of works and tasks, conditions (rules) of coordination between executors. 
Control and monitoring of performanceresults lead to creating measures for controlling procedures and parameters for the assessment of actual results relevance. Decision making process taking place after implementation determines functional dependencies for factor analysis of the results, forming initial base and the list of possible correcting activities or replanning.

Methodology of the indicative planning in the sphere of education should take into account a number of peculiarities of management objects:

$\boldsymbol{\Delta}$ territorial isolation, conditioning the necessity to form information and communication networks with highly developed infrastructure, high throughput capacity and other characteristics that should be implemented at the stage of making an indicative plan for developing territorial educational segments;

$\Delta$ diversity of existing technical devices and programs for different types of educational institutions. It is connected with irregular information support of educational institutions at previous time-periods that now leads to the diversity of the inherited information systems, making management more difficult;

$\boldsymbol{\Delta}$ weakmanageability and instability of educational systems resulted from non-linear development conditioned by innovations. Instability is caused by unstable character of development of consumption market of educational services, incomplete character of structural-and-content reformation of Russian system of education, problems in information supplement of the education management sphere, inaccuracy whiledescribing facts and events of education processes and etc.;

$\boldsymbol{\Delta}$ actually delayed character of educational system management. Lag effect is connected with the influence of external factors and objective demand to transform accidental influences and non-relevant information into well-g rounded rules of conduct, as well as with the specific character of interaction between consumer of educational services and surrounding social sphere[2].

Methodology of the indicative management of education systems is characterized by interdisciplinary character.

\subsection{Concept as a Characteristic Feature of Multidimensionality Me thodology}

Concept of the indicative management model of educational system development is defined by the methodology of multidimensionality. Interdisciplinary aspect is the functional nucleus supporting stability in dimensionality. It is characterized by the following concepts and notions: components of the human capital assets, education investments, targeting orientations of education subjects development; significance of the complex institutionalization of education, economy and society, analysis of educationalinstitutions by means of the methods of economic theory, education and socially-economic policy as autonomous and mutually supplemented patterns; regulation method, indicative planning; subject, peculiarities, models of process development, target programs.

Thus, concept is methodology of the mu lti-dimensionality, characterized by basic theoretical models, specified by certain conceptsat the level of projecting elaborations. So, methodology of multidimensionality stipulates the diversity of content features of the concept: concept is defined as the phenomenon of methodology; concept is defined as a notion. Meanwhile the concept stands for methodology and defines the content of the notion. This structure is universal. The content of the construct is variable and is defined by time, social, cultural, and economic aspects of objective reality.

\subsection{Content of the Concept-methodology "Upbringing" and Other Concepts as the Basis for Forecasting Manage ment of Educational Systems Development in Russia}

Now we'll go into greater detail revealing the concept-methodology "upbringing" which contains a number of other concepts and characterizes educational reality of contemporary Russia. This concept is treated asone of the basic factors in forecasting management of educational systems development.

Education is a process of personality's spiritual development. To "teach" means to give information, to develop skills, to gain knowledge.To "bring up" means to contribute to the soul development, to provide personality with so me moral criteria. However, it is impossible to bring up without teaching, and teach without bringing up.

Teaching is the leading power of information and operation development, main result of which being acquiring a culture of meanings and sensesby a person. Targets of upbringing includedeveloping motives, ideals, attitudes, self-consciousness of aims, values and personal orientations. Upbringing as a leading power of motivation and value development of a person is focused on the sphere of his subjective world. It is upbringing that makes it possible to acquire culture meaning by a person as a part of educationalprocess. According to M.Sheller, education, if considered as a culture of soul, is the category of a person's existence[3]. It is the form in which he or she exists. Education content, stipulating everyday context of person's existing, should be aimed at providing integration of upbringing influences. It means that the main principle of education content construction at modern higher schools is integration. In its turn it should be based onhumanization, humanitarization and fundamental character of scientific knowledge, anthropocentrism and culture relevance. Let's touch on the above mentioned issues in detail. It should be mentioned that the categories humanization and humanitarization, in terms of constructingeducational content based on integrationat higher school, require corresponding interpretation. Humanization and humanitarization "overlap" in their meaning. The word "humanis m" is derived from "humanus", i.e. human, while "humanitarity"-comes from humanitas - human nature. However, these notions are not equal. 
Humanization is some kind of spirit of the time, reality of modern educational system. Human itarization is connected with overcoming technocratic and scientific tendencies and split of culture and education into the humanities and technocratic components.

In modern philosophy there is a viewpoint that the notions "humanitarian or liberal sciences" and "humanitarian knowledge" are not semantically equal.It makes it possible to search for humanitarian knowledge within non-humanitarian disciplines. At the same time, humanitarian knowledge itself is not as significant as its tendency to create humanistic outlook in every student as part of educational process. It means that humanitarian knowledge stands for personal knowledge. Subjective scientific knowledge should be introduced into the content of education. To humanize education means to make it personality-oriented, subjectively significant for every person. Each discipline should reproduce fundamental ideas, logics and structure of corresponding sciences in an abstract and adequate way. In this case it becomes fundamental.

Fundamental character of education is interpreted as the process, aimed atdevelopingintegral scientific worldview and personal intellectual prosperity. Fundamental aspect of education means its orientation atrevelation of essential background and links between different phenomena of the surrounding world. It is integral fundamental knowledge that makes it possible create the student's worldview.

Worldviewcan be treated as an analogue model. It presents the synthesis of scientific abstracts with perceivedby sensesimages of reality. Worldview is created by all forms of consciousness: ordinary, scientific, philosophic, and extra-scientific (fiction, religious and mythological etc.) and contains images that cannot be described by means of logics.

We find it relevant to speak about subjective worldview created by each student. The student becomes notional and organizational centre of education, integrating in his or her mind various types of knowledge that results in new knowledge and a subjective worldviewin particular. Anthropocentric character of modern education is expressed in sucha way.

It should be also pointed out that educational system is a special, scientifically grounded culture image. Education is a microcosm of culture; it presents the part which at a small scale reproduces culture in its integrity and at the same time in the form of inner differentiation. Scientific backbone of culture is presented in the system of scientific disciplines. In the course of education, a student masters systematic knowledge from a certain sphere of culture and historic activity, identifying his or hermental activity with this or that integral fragment of cultural reality. Consciousness is integral, it introduces integrity into the world. It tends to be the same in the sphere of education. The idea of culture conformity of education is that culture is presented as amodel-image in accordance with which it is self-organized. Education as a model of culture is also revealed as a sphere where, ata s mall scale, ma in processes that used to occur, are taking place and are expected in the futureare concentrated and reproduced [4]. Thus, integration is the key princip le of education content construction at higher educational institutions. The princip les of education content integration are humanization, human itarization, fundamental character of scientific knowledge, anthropocentrism and culture conformity.

In Russian pedagogy integration as a scientific term appeared in the first half of 1980s. However, historical record of introductionof the term integration in education corresponds to the beginning of XX century.

In Russian and foreign pedagogy, researchers pay great attention to the issues of integration. Today we can witness integrative and pedagogical approaches that came to be understood as unities of systematic views, principles and ideas, determining main trends and content of integrative pedagogical activity in this or that sphere at different levels of achieving educational and upbringing aims and tasks.

In his books V.I.Zagvyazinsky worked out the main principles of the concept of interdisciplinary integration of pedagogical knowledge: defined its factors, principles of integrative pedagogical conceptionsconstruction, initial ideas, comprising the core of general pedagogy and tendencies (mechanis ms) of its development.

G.N.Serikov worked out the concept of integral educational picture having targeted social order ("certain acquired accomplishments") in its centre[5]. Education processes integrating teaching and learning, tutorship and mastering skills play an important role in this picture. In total,acquired accomplishments and educational processes make up a part of integrative education picture reflecting those aspects of education that directly involve students. It means that integration of educational processes leads to the development of students' independence due to mastering social experience reflected at a high level of personal accomplishments.

The concept of integration of general and professional education is presented in the books byM.N.Berulava[6]. According to his point of view, "integration of educational content" shows integrity of content and procedural aspects and is relevant to all levels of educational content. They include general theoretical idea of the discipline, teaching materials, pedagogical activity and personality. Objective bas is for integration of general and professional education, according to M.N.Berulava, is integrating processes taking place in science, technology and production. The main tendencies of integration of science, technology and production in a didactically adopted way can be integration of general and professional education. He distinguishes structure and typological characteristics of education content integration as well as its factors, functions, and principles.

Nowadays there are a great number of such conceptions and systemsin pedagogy, adding to the general integrating picture. However, creation of such really integral picture in pedagogy requires strengthening integral work aiming at making synthesis deeper. We mean synthesis: a) within the 
conceptions themselves (resources); b) between conceptions (resources); c) between conceptions and resources. It is important to take into account that this separation of pedagogical works into "resources" and "conceptions" is quite relative.

It's alsoworth noting that modern pedagogy sticks to the point that spirituality is correspondent not only to the world expressed in books, pictures, music compositions, thoughts, but also to the deep consciousness of the student. It is aimed at collaboration between a teacher and a student that is possible only in terms of their relevantly equal rights as subjects of educational process, as subjects of educational integration. In this way, integration is not only a formal combination of different kinds of knowledge into a new academic text but the combination of different texts in the mind of a student leading to the formation of mental notions and sense structures. Student's mind is the leading factor of educational integration[7]. Thus, the category of subjectivity of human nature becomes the leading one. "In the course of life in society, -in B.F.Lomov's words - each person develops a complicated, many-sided, many-levelled and dynamic system of subjective and personal relations". It could be described as subjective space where each dimension corresponds to certain subjective and personal attitude (labour, model, events, etc.)[8].

In psychological and pedagogical researches, the categories "space" and "field" are synonymous. Taking into account the fact that certain mental connections occur during activity, forming a special sphere, special relevantly independent plane of reflection (different from the plane of definite interrelations, aims, actions and operations), B.S.Bratus comes to the conclusion that there is a certainnotional field and activity field. The first is defined as construction of notions, the second as everyday layer of mental work, expressed in images, ideas, meanings, decision programs, actions and etc. Field of notions makes up a special psychological "substance" of a personality, defining his or her own personal layers of reflection.

B.S.Bratusfinds it possible to speak about subjective space of a personality, pointing out the following coordinates: person's being, defined as a system of activitiessubstituting each other; culture as a system of mean ings, programs, patterns, norms, ru les and etc.; notions referred to as "meaning of meanings", as dynamic systems of consciousness, reflecting spatial relations of a man and reality, revealing this reality in his or her mind [9].

Subjective space has the meaning of personal "sense field" as an integral structure. Consequently, ideal integration model in education is presented by a subjective space of a personality, interacting with the world according to the coordinates of being, culture, and senses. Meanwhile, ideal model of education and integrative spaces including humanitarian, natural scientific and professionally oriented knowledge at the level of coordinates is presented by the categories "culture" and "sense". Personal existence makes it possible to provide "mutual penetration" of subjective and educational integral spaces making the process of their non-linear develop mentdynamic, encouraging the enrich me nt of the common sense field.

The category "non-linear development" refers to quite a new sphere of scientific researches-synergetics. Synergetics (derived from Greek sinergetios-joint, acting in concord) is an interdisciplinary trend dealing with self-organization laws and co-evolution of co mplicated systems of any nature irrespective ofthe nature of the elements comprising them. Synergetics playsa specific role in the system of education. According to the key aspects of this science, integration of natural sciences, humanitarianand professional knowledge contributes tomultidimensional character of one and the same notions in different meaningful contexts. Thus, thinking activity of students is stimulated and it contributesto expansion of the sense field of a personality.

Synergetic approach to education means stimulating or awakening education - education treated as self-d iscovery, as collaboration with oneself and others.

Education targeting means providing some small-scaled resonance impacts focused on self-managed and selfsupported development of a person. Non-linear situation, condition of instability of non-linear sphere, its sensitivity to small impacts (fluctuations) are connected with the indefiniteness and possibility of making choices. A person selects the most beneficial way, relying on his or her own personal integral ideas. However, it should be mentioned that the choice of the way is determined by inner features of a comp licated system being one of the realized ways.

From synergetic point of view, education is a non-linear situation of an open dialogue, during which hidden potentialis revealed in a student, aspirations (structuresattractions) for positive and promising trends of his or her own development.

Due to its interdisciplinary character, synergetics draws natural sciences and humanitarian knowledgecloser to each other, creating educational space making up necessary sphere for developing a personality able to think synergetically. It means to think in a non-linear way, alternatively, presupposing the possibility to change development pace and make qualitative changes into a situation.

Perception of realia images of the surrounding world is integral. Education can be interpreted as transmission of integral informational blocks, qualitative changes of schemes, thinkingpatterns.

Continuous process of education, self-education, and creative activity is connected with a series of events, significant reconstruction of attractors, kind of phase transference. Thus, synergetics, revealing the principles of ass embling something complicated out of the simple, makes up a new "philos ophy of value".

The essential triad for synergetics is openness non-linear character - non-equilibrium. Upbringing,at the bottom, is a system synergetic process where such objective substances as targeted upbringing activity of a teacher, self-perfection of a personality and influence of social and pedagogical infrastructure, upbringing environment and 
personality's development interact with each other.

Interdisciplinary approach to modelling education content in modern higher educational establishments enables students to master different ways of cognition of the world, science, art, and philosophy. Only many-sided way of knowledge acquisition provides its deep interpretation i.e. interpretation of its essence, penetrating into its characteristic features. In this process creativity and search for personal senses play the greatest role. Key principle of educational content integration realized in terms of higher educational establishments makes it possible to create a model of humanitarian educational sphere of a higher school. Its significant features are as follows: openness, integration, professional orientation. This model is aimed at upbringing and developing an intelligent person, acquiring high moral and creative potential, professional and social mobility[10].

Humanitarian upbringing and developing environmentis referred to as an external surrounding for the subject of educational process. Plunging into it allows usingcertain information flow for the purpose of alteration, perfection of the human "I".

Upbringing in terms of integral world interpretation provides formation and development of integral personality able to change, develop, improve, and acquire culture of personal senses. All these issues stipulate considering upbringing treated as personality development as value and notional bas is of modern educational content.

\subsection{Characteristic of the Concept-methodology "Model of Indic ative Manage ment of Educ ational Systems Development"}

Modern multi-dimensional objective reality makes it possible to substantiate the model of indicative management of the educational systems development focused on ensuring high quality of education in contemporary Russia as a concept of multi-dimensional methodology.

The analysis of education state at lower levels is the background for projecting regional/municipal programs and long-term, middle-term and short-termindicative plans. In this way it becomes possible to achieve or at least get closer to the achievement of the standard set by the government.

High quality is the basis of strategic management, defined as the process consisting of several stages and functions, including the following ones: strategic analys is, strategic forecasting, strategic planning, strat egic organization and motivation, strategic control and regulation. Each stage is completed atthe achievement of some result.

Strategy in terms of quality management ineducational system is considered as the system of actions, limited by the frames of the indicative plan. Its characteristic features are predetermined by the principles of its universal character, information interaction, account of state assessment of educational system, account of educational infrastructure resources in terms of development, reflexivity of educational system that is characterized by the notions - stability, manageability, individuality, self-organization.

Social-and-economic policy of the state stipulates the conceptual relevance of indicative planning. Implementation of indicative management model is the indicator proving the selected strategy or urgent need in its correction to support stability of functioning and development of Russian educational system.

\section{Conclusions}

1. Management of education as a dynamic system requires forecasts on the prospects of its development in order to make necessary managing decision.

2. Stable development of education as a social system and institution, as well as stable development management, are possible when the following key principle - principle of social suitability of projecting changes - is followed. This principle should lead to such results that meet the demands of the society.

3. The instrument of the state regulation of functioning and development of education system is indicative management. Indicative management is the method of economics regulation basing on integrity of interrelated and well-balanced mechanisms of interrelation with other methods of regulation, including the following: marketing, monitoring, conception of economic growth, etc. Indicative management is based on the harmonization of actions by authorities and institutions arranging the system of education, focused on stable development in education and improving its quality.

4. Methodology of the indicative management of education systems is characterized by interdisciplinary character.

5. The existing dimensional objective reality enables to ground the methodology of the dimensionality as the concept of indicative management model of educational system development, focused on providing high quality in modern Russianeducation.Interdisciplinary aspect is the functional nucleus supporting stability in dimensionality.

6 . The main principle of education content construction at modern high schools is integration that should be based onhumanization, humanitarization and fundamental character of scientific knowledge, anthropocentrism and culture relevance.

7. The ideal model of integration in education is presented by creating subjective space of a personality, uniting his or her existence being, culture, senses.

8. Personal existence makes it possible to provide "mutual penetration" of subjective and educational integral spaces making the process of their non-linear development dynamic, encouraging the enrichment of the common sense field.

9. Synergetic approach to education means stimu lating or awakening education - education treated as self-d iscovery, as collaboration with oneself and others.From synergetic point of view, education is a non-linear situation of an open 
dialogue, during which hidden potential is revealed in a student, aspirations (structures-attractions) for positive and promising trends of his or her own development.

10. Perception of realia images of the surrounding world is integral. Education can be interpreted as transmission of integral informational blocks, qualitative changes of schemes, thinkingpatterns.Upbringing,at the bottom, is a system synergetic process where such objective substances as targeted upbringing activity of a teacher, self-perfection of a personality and influence of social and pedagogical infrastructure, upbringing environment and personality's development interact with each other.

11. Social-and-economic policy of the state stipulates the conceptual relevance of indicative planning. Implementation of indicative management model is the indicator proving the selected strategy or urgent need in its correction to support stability of functioning and development of Russian educational system.

\section{REFERENCES}

[1] Prisyazhnaya A.F. Pedago gical for ecasting within the system of continuing pedagogical education: methodology, theory, practice: thesis ... of Ph.D. of pedagogy: 13.00.08. RSL. Chely abinsk. Russia, 2007.P. 53
[2] Gaponyuk P.N., Karpova N.K., Gujhelya D.J. Theory and Practice of Indicative Management of Educational System Development in Russia. Rostov-on-Don: PH Southern Federal University, 2011. 244 p.

[3] Scheller M. Selections / Ed. By A.V. Denezhkin. M., 1994. $490 \mathrm{p}$.

[4] DanilyukA.Ya. Theory of education integration. Rostov-on/ D, 2000. 440 p.

[5] Serikov G.N. Education: aspects of reflection system. Kurgan, 1997. 464 p.

[6] Berulava M.N. The humanistic education in terms of information civilization // Pedago gy. 2008. №7. P. 3-7.

[7] DanilyukA.Ya. Theory of education integration. Rostov-on/D, 2000. P. 176.

[8] Lomov B.F. Methodological and theoretical problems of psychology.M., 1984. P. 130.

[9] Bratus B.S. On the problem of man in psychology // Questions of psychology. 1997. №5. P. 3-19.

[10] Karpova N.K., Mareev V.I., Schipankina E.S. Culture Approach in Modern Education and Upbringing. Saarbrücken: LAP LAMBERT Academic Publishing GmbH \& Co. KG, 2012. 194 c. 